\title{
Editorial: Reaching New Heights: Recent Progress in Paleotopography
}

\author{
Paolo Ballato ${ }^{1 \star}$, Carina Hoorn ${ }^{2}$, Alexis Licht ${ }^{3}$, Katharina Aenne Methner ${ }^{4}$ and Heiko Pingel ${ }^{5}$ \\ ${ }^{1}$ Department of Science, University of Roma Tre, Rome, Italy, ${ }^{2}$ Paleoecology and Landscape Ecology, Institute for Biodiversity \\ and Ecosystem Dynamics (IBED), University of Amsterdam, Amsterdam, Netherlands, ${ }^{3}$ Aix-Marseille Université, CNRS, IRD, \\ INRAE, CEREGE, Aix-en-Provence, France, ${ }^{4}$ Department of Geological Sciences, Stanford University, Stanford, CA, \\ United States, ${ }^{5}$ Institute of Geosciences, University of Potsdam, Potsdam, Germany
}

Keywords: mountain building, orogenic plateaus, paleoaltimetry, stable isotopes, computational modeling, landscape evolution

\section{Editorial on the Research Topic}

\section{Reaching New Heights: Recent Progress in Paleotopography}

Although mountain belts and orogenic plateaus occupy only a limited portion of the Earth's surface (about $4 \%$ above $2 \mathrm{~km}$ in elevation), they are among the most prominent landscape features with global implications for tectonic deformation, climate, hydrology, and biodiversity. Topographic growth locally modifies the crustal stress field and the locus of active deformation; it re-arranges fluvial networks and atmospheric circulation patterns; it generates highly asymmetric precipitation and marked temperature gradients, and favors the development of diverse ecosystems over geographically limited areas; it thus dramatically impacts biodiversity and the evolution of flora and fauna over geological scales.

In recent years, a growing number of studies have tried to investigate the chronology and amplitude of topographic growth in deep time (millions of years), using various field-, laboratory-, and computer-based approaches from a wide range of scientific disciplines. The accuracy and uncertainty associated with these approaches are still being discussed, and studies providing quantitative paleoaltimetry estimates remain rare despite their relevance. Moreover, most quantitative studies so far have concentrated on the youngest and most extensive mountain ranges such as the Himalayas or the American Cordilleras, while the topographic evolution of smaller or much older orogens remain virtually undocumented.

This Research Topic contains 11 articles covering a wide range of paleotopography research, from short reviews and perspectives of either established or innovative paleo-topographic approaches, new datasets and syntheses of topographic uplift in well-known and understudied areas, and outlooks on the future development and improvement of paleoaltimetry.

Botsyun and Ehlers present recent advances and caveats in high-resolution isotope-based general circulation models (iGCMs) to calibrate stable isotope paleoaltimetry approaches, a growing and dynamic direction for paleotopographic reconstructions. Hren and Ouimet propose a new method to quantify paleotopography based on the isotopic signature of organic molecular biomarkers integrated over river catchments. Following the recent development of triple oxygen analysis, Chamberlain et al. review the application of this method to crystalline rocks and their high potential for paleoaltimetry on the crystalline cores of mountain belts. Ibarra et al. propose to use triple oxygen on lacustrine sediment as a paleoaltimetry tool, which they combine with carbonate clumped isotope data to reconstruct the paleoelevation of Eocene Nevadaplano rocks (North American Cordillera).

Gébelin et al. report present-day stream water isotopic lapse rates from the west facing slopes of the equatorial Andes in Ecuador, underscoring that tropical regions can be targeted for future paleoaltimetry studies. Ingalls and Snell provide an exhaustive review of state-of-the-art and emerging tools to investigate the diagenetic alteration of carbonates, a crucial step in stable isotope paleoaltimetry, with an illustration of their impact on Tibetan paleoelevation estimates. 
McLean and Bershaw investigate the isotopic composition of carbonates while Kukla et al. focus on authigenic clays in paleosols from the John Day Formation (Eocene to Miocene), United States, in the rainshadow of the modern Oregon Cascades, with contrasting interpretations regarding the evolution of regional topography.

Beyond stable isotope paleoaltimetry, Montes et al. combine field mapping and detrital zircon geochronology to show that the northern and central Andes were separated between ca. 13-4 Ma by lowlands that connected this region with western Amazonia at ca. $3^{\circ} \mathrm{N}$, providing a pathway for biotic exchange. Fox et al. examine the role of fluvial reorganization in the formation of elevated landscapes that resemble uplifted formerly contiguous low-relief landscapes. Taking the southeastern Tibetan highlands as an example, they propose that an interpolated paleosurface across low-relief remnants cannot be used to robustly measure geodynamic processes in space and time. Finally, Heitmann et al. review the recent paleoaltimetry work from the Colorado Plateau and propose several test studies to fill the gap in its uplift history.

In summary, this research topic presents new ideas, tools, and results on a wide range of aspects of the paleotopography of mountain and plateau regions around the world. It emphasizes that the future of paleoaltimetry has to be interdisciplinary and combine multiple proxies, considering the numerous uncertainties of individual tools. To increase their robustness and accuracy, the next generation of paleotopography studies will have to incorporate results from a variety of approaches, which is well-illustrated by the array of methods and applications in the eleven articles of this research topic.

\section{AUTHOR CONTRIBUTIONS}

All authors listed have made a substantial, direct and intellectual contribution to the work, and approved it for publication.

Conflict of Interest: The authors declare that the research was conducted in the absence of any commercial or financial relationships that could be construed as a potential conflict of interest.

Publisher's Note: All claims expressed in this article are solely those of the authors and do not necessarily represent those of their affiliated organizations, or those of the publisher, the editors and the reviewers. Any product that may be evaluated in this article, or claim that may be made by its manufacturer, is not guaranteed or endorsed by the publisher.

Copyright (c) 2021 Ballato, Hoorn, Licht, Methner and Pingel. This is an open-access article distributed under the terms of the Creative Commons Attribution License (CC $B Y)$. The use, distribution or reproduction in other forums is permitted, provided the original author(s) and the copyright owner(s) are credited and that the original publication in this journal is cited, in accordance with accepted academic practice. No use, distribution or reproduction is permitted which does not comply with these terms. 